\title{
Characterization of ultramafic mine tailings reactivity for carbon capture, and storage
}

\author{
X. LU ${ }^{1 *}$, G.M. DIPPLE ${ }^{1}$, C.C. TURVEY ${ }^{1}$
}

${ }^{1}$ Department of Earth, Ocean and Atmospheric Sciences, University of British Columbia, Vancouver, British Columbia V6T 1Z4, Canada (*correspondence: xlu@eoas.ubc.ca, gdipple@eoas.ubc.ca, cturvey@eoas.ubc.ca)

As the effects of anthropogenic climate change become more significant, there is an increased necessity and demand for developing carbon capture and storage strategies. Carbon mineralization (also termed mineral carbonation) is one of the many strategies that can sequester carbon dioxide $\left(\mathrm{CO}_{2}\right)$ in mine tailings that have high $\mathrm{Mg}$ content (e.g. ultramafic $\mathrm{Ni}$, diamond, $\mathrm{Pt}$ and $\mathrm{Cr}$ ) through the liberation of $\mathrm{Mg}$ cations and the subsequent precipitation into $\mathrm{Mg}$-carbonate minerals. Mineral carbonation will serve to reduce mine site $\mathrm{CO}_{2}$ emissions and generates environmental benefits including dust mitigation, tailings stabilization, and toxic metal encapsulation.

During the reaction process of carbon mineralization, mineral dissolution can be the rate-limiting step that controls the amount of available $\mathrm{Mg}$ cations and the carbon sequestration potential of mine tailings. To enable low-cost carbonation, technologies that work at atmospheric conditions need to be targeted, and the release of the readily leachable, loosely bounded portion of the total $\mathrm{Mg}$ at atmospheric condition is therefore explored and termed "labile Mg."

Here, we explore what factors control the labile Mg content of minerals and mine tailings to better define their reactivity for carbon sequestration. Flow-through dissolution experiments were conducted on different minerals and tailings dissolving in $\mathrm{HCl}, \mathrm{HNO}_{3}, \mathrm{H}_{3} \mathrm{PO}_{4}, \mathrm{H}_{2} \mathrm{CO}_{3}$ at different acid strengths. Results show of the acid types tested, $\mathrm{H}_{2} \mathrm{CO}_{3}$ releases the most labile $\mathrm{Mg}$ for a given mineral or mine tailings. Brucite $\left[\mathrm{Mg}(\mathrm{OH})_{2}\right]$ and pyroaurite $\left[\mathrm{Mg}_{6} \mathrm{Fe}^{3+}{ }_{2} \mathrm{CO}_{3}(\mathrm{OH})_{16} \cdot 4 \mathrm{H}_{2} \mathrm{O}\right]$ are highly reactive with high abundance of labile $\mathrm{Mg}$ compare to $\mathrm{Mg}$-silicates serpentine $\left[\mathrm{Mg}_{3} \mathrm{Si}_{2} \mathrm{O}_{5}(\mathrm{OH})_{4}\right]$ and forsterite [ $\left.\mathrm{Mg}_{2} \mathrm{SiO}_{4}\right]$.

The labile Mg content of mine tailing thus depends on their mineral composition and dissolution environment (acid type+strength). This will influence the amount of labile $\mathrm{Mg}$ for reaction at a given mine site. This knowledge can then be combined with information regarding mine site emissions from electricity generation and mine trucks to determine the sources of $\mathrm{CO}_{2}$ and the capacity of the tailings to sequester $\mathrm{CO}_{2}$. 